\title{
Cibercultura
}

\section{Uma experiência de inclusão digital na Amazônia: - Programa NavegaPará e o horizonte da democracia representativa. Limites e esperanças}

An experience of digital inclusion in Amazon: the NavegaPará program and the horizon of representative democracy. Limits and hopes

FÁBIO FONSECA DE CASTRO

Professor do Programa de Pós-Graduação Comunicação, Cultura e Amazônia - UFPA.

<fabio.fonsecadecastro@gmail.com>

Dayane Correa Pantoja Baía

Mestranda do Programa de Pós-Graduação Comunicação, Cultura e Amazônia - UFPA.

<dayanebaia@hotmail.com>

\section{RESUMO}

O objetivo deste artigo é refletir sobre a estratégia de Inclusão Digital na Amazônia tendo como referência o Programa NavegaPará, desenvolvido pelo governo desse estado em parceria com a Eletronorte, o Governo Federal, prefeituras municipais e organizações da sociedade civil. Procura-se compreender como o referido programa é concebido a partir da proposta de um modelo de desenvolvimento regional que crie alternativas para a condição de "desenvolvimento restringido" imposto à Amazônia pela mentalidade sudestina e, em o fazendo, também se procura compreender a dimensão política presente na noção de Inclusão Digital. Palavras-chave: Inclusão digital; Amazônia; Desenvolvimento.

\section{ABSTRACT}

The aim of this paper is to discuss the strategy of Digital Inclusion in Amazon. We observe the NavegaPará Program, developed by the Pará government in partnership with Eletronorte, the Federal and municipal governments and civil society organizations. We seek to understand how this program dialogues with a regional development models to create alternatives to the status of "limited development" imposed over the Amazon by the mentality of Brazilian southeast region - political and economical centre of the country. We also seek to understand the political dimension present in the notion of Digital Inclusion.

KeYwords: Digital inclusion; Amazon; Development. 
A s promessas de democracia trazidas pela cultura digital parecem responder aos A paradoxos da democracia representativa colocados por diversos pensadores contemporâneos, como Bohman (1996); Pateman (1992); Santos (2002) e Bobbio (2007) para os quais há uma contradição inerente, eventualmente estrutural, entre a tendência universalizante das formas democráticas e o concomitante distanciamento da esfera civil do campo de decisão política. A internet e suas práticas, por seu caráter ubíquo, universalizante e arquivístico tenderiam a concretizar essa possibilidade, sugerindo meios para, tecnicamente, ampliar a participação política para além da escolha de representantes. Seria uma nova possibilidade de sedimentação, enraizamento e desenvolvimento da democracia, tal como compreendido por alguns autores, dentre os quais Scheer (1997), Lévy (1999) e Norris (2001), enquanto que outros mais, como Kumar (1997) e Jordan (2001), consideram que a cultura digital consiste, na prática, num processo de consolidação de padrões socioculturais individualistas existentes na contemporaneidade.

A hipótese de que a cultura digital valoriza as práticas de colaboração, participação e interação social, contribuindo para uma resignificação da política, resta a ser avaliada e discutida. O Programa NavegaPará, desenvolvido pelo governo desse estado como uma de suas políticas prioritárias, durante a gestão do Partido dos Trabalhadores (PT), entre 2007 e 2010, contribui para agregar alguns elementos empíricos sobre essa discussão.

Trata-se de um programa de Inclusão Digital (ID), mas sua dimensão profunda, aquela que produz sentidos para além da estrutura física - obviamente necessária para a ID, mas que não esgota seu sentido -, consubstanciada por um debate reflexivo no campo da economia política a respeito do que seria um Novo Modelo de Desenvolvimento para a Amazônia (NMDA), pensa a ID como cidadania e participação social no debate público. Com efeito, pode-se indagar sobre as sucessivas camadas 
de sentido presentes na noção de ID: a inclusão meramente como acessibilidade, a inclusão como capacitação para a produção de conteúdo, a inclusão como participação em torno de questões pontuais e a inclusão como vínculo político e social.

O Programa NavegaPará se apresentou, publicamente, como "uma rede pública e gratuita de comunicação, no coração da Amazônia, onde as distâncias continentais e a dificuldade de acesso são entraves históricos" (Pont, 2008, online). Sua missão era levar a cidadania digital à populações desfavorecidas e promover a integração territorial de um estado com 1,1 milhão de quilômetros quadrados, grandes lacunas de infraestrutura de transporte e comunicação e ocupado de maneira dispersa. Essa missão, tal como publicamente declarada no material publicitário do programa, atinge plenamente a concepção que o senso comum atribui ao sentido de ID. Algo também presente no seguinte trecho do mesmo material, embora com alguns acréscimos que gostaríamos de destacar:

O Navega é uma plataforma para o futuro, que, para além da inclusão digital e da interligação de órgãos públicos em mais de 50 municípios, permite a implantação de novos programas e projetos, atualizando tecnologicamente o Estado quanto ao uso da internet e à formação de mão de obra especializada."

(Pont, 2008, online)

O que destacamos é o compromisso, declarado, com a "atualização tecnológica do Estado" e com a "formação de mão de obra especializada". São pistas para essa visão 
mais aprofundada do projeto, objeto de nossa discussão. Há, nesses compromissos, uma formulação de natureza política que sugere uma crítica ao modelo econômico vigente, como se verá e que, ao fazê-lo, possibilita a atualização dos paradoxos da democracia representativa e a sedimentação de uma maior interação social.

\section{O programa NavegaPará}

O NavegaPará teve um desenvolvimento rápido e conseguiu ser uma das principais representações do mandato do Partido dos Trabalhadores no governo paraense. O programa foi estruturado a partir de dois convênios, negociados nas primeiras semanas do governo: um deles com a Metrobel, rede de fibra óptica unindo instituições científicas da Região Metropolitana de Belém e, outro, com a Eletronorte, por meio do qual a estatal cedeu, ao estado do Pará, os $1.800 \mathrm{~km}$ de sua rede de fibra óptica.

A estratégia tecnológica utilizada pelo programa foi a conjugação da fibra óptica com o sinal de rádio. Trata-se de uma solução híbrida, efetivamente inovadora, porque a solução mais provável seria o uso de satélite, mas que teria o custo potencialmente elevado, num espaço de dimensões amazônicas.

A partir dessa estrutura, vieram outras etapas do projeto:

1. Implantação de onze cidades digitais (Santa Maria, Abaetetuba, Barcarena, Belém, Marituba, Tailândia, Tucuruí, Jacundá, Marabá, Pacajá, Altamira, Uruará, Rurópolis, Itaituba e Santarém);

2. Implantação de 186 infocentros em cerca de 50 dos 143 municípios paraenses aqueles atendidos pelas infovias estabelecidas;

3. Conexão de 600 escolas à rede;

4. Ampliação da rede de infovias para outras regiões paraenses.

As cidades digitais podem ser compreendidas como espaços públicos com possibilidade de conexão livre, gratuita e em alta velocidade, à internet. Em termos 
práticos, tratava-se de obras de construção de torres de 80 metros de altura, bem como de estruturação cabos ópticos, instalação de postes e de outros equipamentos e, ainda, materiais necessários para sua efetivação, tais como equipamentos DWDM e SDH nas salas de telecomunicações e a instalação de equipamentos de rádio Wimax nas torres.

Os infocentros, tanto aqueles abertos ao público em geral, como também os que eram chamados "infocentros de negócios", destinados ao uso comercial de micro e pequenos empresários, demandavam obras físicas (edículas) de tamanho variável conforme o contexto local e as parcerias estabelecidas com prefeituras, igrejas, centros comunitários - e a instalação dos equipamentos de acesso para os clientes da rede, o governo em seus diversos níveis e sociedade.

Em relação à infraestrutura de comunicação digital das escolas, aí incluídas salas de informática, sistemas de recepção por rádio e softwares, o Governo do Estado atuou em parceria com o Governo Federal, procurando agilizar a implantação, no Pará, do Programa Banda Larga nas Escolas, promovido pelo Governo Federal em parceria com as concessionárias de telefonia fixa. O Plano Geral de Metas, da Agência Nacional de Telecomunicações, substituiu a obrigatoriedade das concessionárias instalarem Postos de Serviços de Telecomunicações (PSTs) urbanos - previstos no Plano Geral de Metas para a Universalização (PGMU) do Serviço Telefônico Fixo Comutado (STFC) - por infraestrutura de rede e manutenção de serviços de banda larga da rede, para conectar as escolas públicas do país. No Pará, graças à estrutura do NavegaPará e aos investimentos do governo em obras físicas nas escolas, sobretudo na adequação dos espaços laboratoriais de informática, o projeto avançou mais rapidamente que em outros estados, ampliando sobremaneira o impacto do Projeto. Em quatro anos, cerca de 600 escolas foram conectadas à rede. 
Outras infovias foram planejadas para alcançar outras regiões do estado do Pará, no que seria um segundo mandato do PT no governo do estado - o qual não houve. O quadro abaixo representa o projeto geral da estrutura de fibras ópticas planejadas:

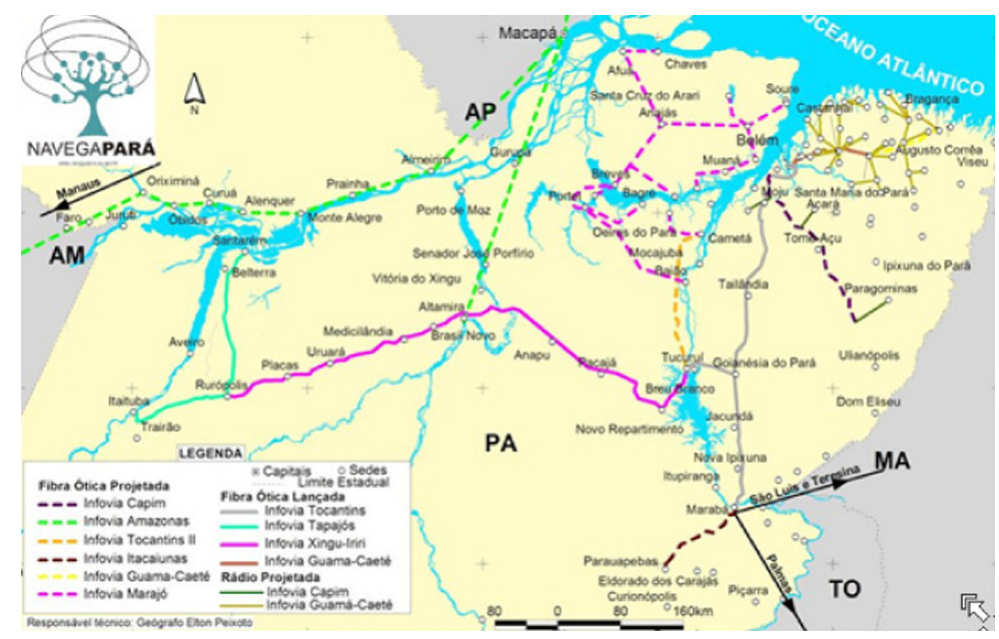

Fonte: Programa NavegaPará, 2010.

Figura 1 - Malha de infovias do NavegaPará

Nele, pode-se observar a estrutura recebida da Eletronorte - as chamadas infovias Xingu, Tapajós, Tocantina e Guamá-Caeté - e um plano de expansão que o Governo do Estado pretendia implantar juntamente com o Governo Federal e que ligaria o Pará aos estados do Amapá e do Amazonas, além de alcançar imensas regiões do Pará ainda não beneficiadas pela inclusão digital. 


\section{A visão estratégica do NavegaPará}

O NavegaPará não constituiu uma ação isolada no contexto das políticas públicas do governo do PT. Para compreendê-lo melhor é preciso situá-lo no conjunto de um programa de ação denominado Novo Modelo de Desenvolvimento para a Amazônia (NMDA), o qual se pretendia, em primeiro lugar, como uma critica à forma como a questão do desenvolvimento regional amazônico vinha sendo, historicamente, tratada. Porém, para além de sua dimensão crítica, o NMDA foi, também, um modelo propositivo de planejamento do desenvolvimento e, nesse sentido, uma plataforma política. Como tal, constituiu uma proposta de mudança estrutural da base produtiva do estado do Pará - e de toda a região amazônica, a termo.

O NMDA partiu do diagnóstico geral de que o modelo de desenvolvimento do estado tomou um forma "restringida", sobretudo a partir do regime militar, responsável pela instauração de um modelo de ocupação predatória e descuidada da Amazônia, um modelo capaz de gerar riqueza mas sem criar concomitantemente, a ampliação do emprego e a distribuição dessas riquezas por setores médios da sociedade.

A crítica ao modelo tradicional de desenvolvimento da Amazônia, expressa no debate sobre o NMDA, está presente, por exemplo, no seguinte excerto discursivo de um documento interno do grupo político que articulou o NMDA:

Nas últimas décadas, políticas ditas modernizadoras e simplificadoras foram implementadas, estabelecendo um quadro bastante contraditório, no qual as expressivas taxas de crescimento do PIB não corresponderam as mesmas taxas de melhora da qualidade de vida e das condições sociais e tecnológicas de nossa população. As marcas profundas ainda são visíveis no Estado do Pará e em toda a região. Na economia, o modelo 
de crescimento foi concentrador de renda e dizimador dos recursos naturais. Nos indicadores sociais, a precariedade da saúde, da educação e da habitação, são expressos no IDH, abaixo da média nacional. No meio ambiente, onde a destruição da natureza, realizada com incentivos governamentais, beneficiou alguns poucos grupos em detrimento da qualidade de vida e da sustentabilidade de processos produtivos ambientalmente responsáveis."

(Partido dos Trabalhadores, 2010)

Trata-se de um discurso, ou melhor, de um fragmento discursivo - talvez num estado precário, inclusive, à medida que se trata de um excerto feito para discussão interna do grupo político que fundamentou o NMDA -, mas ela demonstra o todo objetivado, ou seja, o compromisso, o horizonte e, assim, um telos político específico. Inclusive, pelo fato de se tratar de um documento destinado à discussão mais fechada, ainda desprovida do caráter de publicização que caracteriza a disputa política. A análise feita ilustra o conjunto de posições que motivam e/ou justificam as ações centrais do programa de governo do PT, no período 2007-10 e, de uma maneira, como se verá, central, o Programa NavegaPará.

Pode-se compreender melhor a crítica socioeconômica feita pelo NMDA observando a pauta exportatória paraense, a qual é baseada em commodities, com predomínio do setor mineral e com uma presença mínima de beneficiados e manufaturados, tanto no setor minerador como no setor agropecuário. Exporta-se minério de ferro, caulim, alumínio e bauxita não calcinada, por exemplo, mas não há uma escala vertical de beneficiamento desses produtos. O resultado é uma economia com baixo padrão de internalização de renda, com baixo padrão de geração de emprego permanente e com duas resultantes gerais bastante visíveis: (a) ausência de im- 
pacto da economia na melhoria estrutural da condição sociocultural da população e (b) baixo padrão de arrecadação de impostos, considerando-se que a arrecadação sobre produtos minerais, como preconiza a Lei Complementar 87, de 1996, também conhecida como Lei Kandir, isenta de ICMS a exportação de matérias-primas e semielaborados.

As situações socioculturais decorrentes da resultante $(a)$ podem ser exemplificadas por meio da evolução pouco expressiva das taxas do chamado "hiato educacional", de analfabetismo e de anos de escolaridade da população paraense. Por exemplo, enquanto a média nacional do Índice de Desenvolvimento da Educação Básica (Ideb), em 2007, para os anos iniciais do ensino fundamental foi 4,2; o mesmo índice, no Pará, foi de 3,1 - o pior resultado de todo o país.

A seu turno, a resultante (b) se exemplifica na disposição setorial da economia paraense, que se mantém praticamente inalterada há décadas. Em 2006, ano que precedeu o início da aplicação do NMDA, por exemplo, a indústria extrativa mineral foi responsável por 23\% do PIB paraense, enquanto que a indústria extrativa agroflorestal foi responsável por $16 \%$, o setor da construção civil por $20 \%$ e o setor de transformação por $41 \%$ que, no entanto, estão dispersos pelas atividades mais diversas, sem uma concentração mais efetiva que lhe confira uma dimensão estratégica e, além disso, dizem respeito às etapas mais primárias de beneficiamento.

O diagnóstico feito pelo PT dessa estrutura econômica e social, pode-se dizer, concentrou-se sobre a necessidade de transformar o modelo de produção de três espaços sociais bem demarcados: o mundo agrário familiar, o setor da indústria mineral e o campo da ciência e tecnologia (C\&T). Naturalmente que a proposta de um NMDA poderia ser adaptada a vários outros setores do governo, como ocorreu, como maior ou menor êxito, mas a visão estratégica da gestão, efetivamente, se concentrou sobre esses três setores. 
A proposta podia ser sintetizada como uma tentativa de superar a condição de desenvolvimento restringido por meio da promoção de uma mudança estrutural na base produtiva do estado, capaz de gerar uma situação de autonomia e independência relativa. Essa foi, teoricamente, a proposta do NMDA.

Em termos práticos, essa proposta engendrou diversos programas de governo, como, para o mundo agrário familiar, os programas Campo Cidadão (apoio à agricultura familiar), Asfalto Participativo (pavimentação de vicinais e estradas que beneficiavam o pequeno produtor), Pará Rural (regularização e titulação de propriedades), e Zoneamento Econômico e Ecológico (readequação da escala do macrozoneamento do Estado de 1,2 milhão para 1,1 milhão e detalhamento das áreas de influência das rodovias Cuiabá-Santarém e Transamazônica, representando cerca de $26 \%$ do Estado), dentre outros.

Para o setor da indústria mineral a estratégia do NMDA se baseou na atração de investimentos privados e públicos por meio da chancela e apoio do Governo Federal. O núcleo desses investimentos foi a sequência das grandes obras do PAC no Pará, todas elas consolidando a integração produtiva do estado: as comportas da usina de Tucuruí, que permitiram a navegação fluvial por todo o rio Tocantins, interrompidas desde 1980; a pavimentação da rodovia Transamazônica, que permite a ligação mais ágil do oeste com o leste do estado e as reformas dos portos de Vila do Conde, nas proximidades de Belém e de Marabá. Junto com essas obras foi desenvolvido um jogo de pressão política que uniu os dois governos petistas contra a Companhia Vale, com o objetivo de fazer com que ela investisse, em Marabá, na instalação de uma planta siderúrgica dedicada à produção de placas de aço utilizando o minério de ferro extraído da região. A capacidade do governo paraense de fomentar a verticalização da atividade mineral é bastante limitada, considerados os custos do setor, e por essa razão a comutação do projeto com o Governo Federal. 
No terceiro espaço de atuação o Governo Estadual teve a seu encargo a criação da infraestrutura de C\&T, elementar, na visão do NMDA, para dar consequência à sua estratégia. E é dentro desse terceiro campo de ação que se encontra o Programa NavegaPará.

Passemos à sua contextualização, para melhor compreendê-lo. O NMDA tinha sua face mais visível, mais compreensível, na criação de um programa ambicioso de investimento em infraestrutura de C\&T. As principais ações nesse campo desenvolvidas pelo gestão do PT no Pará, foram as seguintes:

1. Multiplicação por nove do orçamento de C\&T do Estado;

2. Criação da Fundação de Amparo à Pesquisa;

3. Criação de três parques tecnológicos (em Belém, Marabá e Santarém);

4. Renovação ou criação de cinco distritos industriais (Belém, Ananindeua, Barcarena, Marabá e Santarém);

5. O Programa NavegaPará propriamente dito, com suas ações específicas:

a) Interligação das principais cidades do estado por meio de uma infovia pública de alta capacidade;

b) Apoio à formação ou ampliação de redes urbanas (infovias) de comutação de dados de altíssima velocidade (Belém, Santarém, Marabá e Parauapebas); Universidades, campi universitários, escolas estaduais, centros de formação tecnológica, escolas agrícolas e sua consequente interligação à Rede Nacional de Pesquisa;

c) Implantação de onze cidades digitais;

d) Implantação de 186 infocentros;

e) Conexão de 600 escolas. 


\section{A compreensão da Inclusão Digital no NavegaPará}

Pode-se compreender a ID como um lugar de fala, uma plataforma de permissividade discursiva, um espaço no qual, a partir de um determinado senso comum, que possibilita o estabelecimento de uma zona de compreensão a respeito de algo, podemse travar batalhas pela significação.

O lugar de fala em questão está estruturado sobre um princípio - efetivamente um ideal - de natureza ético-democrática, que fundamenta a grande maioria das enunciações referentes à ID. Esse princípio, equivalente a uma cápsula discursiva que delimita o lugar de fala ID, ancora-se numa perspectiva de valorização da acessibilidade à comunicação digital como valor democrático superior.

A percepção dessa dinâmica está presente em Cazeloto (2003), quando esse autor afirma que o uso do termo democracia, em referência à ID, aponta para duas classes discursivas distintas que, muitas vezes, misturam-se na diversidade das práticas sociais que as utilizam e formalizam sua enunciação. A primeira dessas duas classes discursivas diz respeito à noção de democracia como "igualdade de acesso". Trata-se de um veio discursivo que procura associar a ID com a democracia, tomando como ponto de partida as múltiplas iniciativas de promoção do acesso coletivo, aí incluídas as diversas formas de subsídio à aquisição, instalação e manutenção de equipamentos, infraestrutura, difusão e utilização de software livre e capacitação de usuários. O motor dessa forma de ação-discurso é a compreensão de que a condição para a democracia é a disponibilização igualitária dos meios pelos diversos níveis socioeconômicos da sociedade. A segunda classe discursiva refere-se, de maneira mais ampla, às transformações socioculturais que a cultura digital produz sobre a própria forma da democracia nas sociedades atuais.

Quando nos referimos à ID temos em mente, portanto, dois fenômenos de natureza sociocultural diferentes. Na primeira classe discursiva, ressalta-se a experiência de 
acessibilidade tecnológica à cultura digital. Na segunda, a experiência política da inclusão numa prática social que reorganiza e resignifica a própria política. Nenhuma das duas formas de compreender a ID é exclusivamente técnica. Ambas possuem uma dimensão sociocultural inerente. A primeira delas é de fácil fruição e aceitação social, ainda que gere diversos embates em relação ao grau de acessibilidade e à responsabilidade cabível, aos diferentes atores sociais, em promovê-la. A segunda, por sua vez, tem um componente deixado, talvez intuitivamente, talvez com certa malícia, mais obscuro.

A percepção de ID inerente ao NavegaPará, pelo que se observa na leitura crítica produzida pelo NMDA, abarca, extensivamente, os dois fenômenos, ou seja, sem deixar de considerar central a materialidade do processo, também reflete a respeito da sua utilidade para a formação e para a instrumentalização política da sociedade. Porém, parece evidente que, nessa linha de pensamento, a simples acessibilidade passa a ser um caminho, necessário, mas não mais que um caminho, em direção à resignificação cultural da política.

Ou seja, seguindo a linha de raciocínio do NMDA, a noção de ID seria mais que, simplesmente, a experiência de acessibilidade tecnológica à cultura digital e a experiência política da inclusão numa prática social que reorganiza e resignifica a própria política. Tratar-se-ia de um processo necessariamente longo, superior ao plano de um mandato, de uma gestão governamental, e, por isso mesmo, plenamente consciente da necessidade prévia de percorrer o caminho da acessibilidade para alcançar a situação posterior, imaginada.

Nessa compreensão, desponta o tema da ciberdemocracia, tematizada por Pierre Lévy (1999) como uma evolução prática do modelo de democracia contemporâneo, uma evolução que se demarca a partir da possibilidade aberta pela inteligência coletiva - em termos práticos, a própria Internet, mas, também, toda a cultura digital, ou seja, as 
diversas transformações, em certo sentido antropológicas, que passam a fazer parte das práticas socioculturais contemporâneas. Na perspectiva desse autor, o "nervo do ciberespaço não é o consumo de informações ou de serviços interativos, mas a participação em um processo social de inteligência coletiva" (Lévy, 1999, p. 194) um ambiente no qual, o "[...] indivíduo é convidado a opinar, a intervir, parecem levá-lo a assumir uma postura mais proativa perante a informação, criticando-a, refazendo-a e interagindo com o produtor e com outros usuários" (Lévy, 1999, p. 194).

Ressaltamos aqui a dimensão de prática cultural no uso da tecnologia: diante das oportunidades e possibilidades de interação, troca, compartilhamento e acesso propiciadas pelos meios digitais, se produz um fenômeno de natureza cultural e política: uma transformação na própria disponibilidade do indivíduo em interagir e participar do espaço social de trocas configurado.

Essa compreensão também está no horizonte das indagações de Scheer (1997) e de Norris (2001). O primeiro sugere que a cultura digital, marcada pelos fundamentos da colaboração e da participação que lhes são inerentes, acaba por produzir um efeito na prática política das sociedades contemporâneas, caracterizado, a um tempo, pela ampliação da disposição à participação política do indivíduo fora dos meios digitais e, num outro tempo, decorrente, pela exigência de transformação e abertura da própria esfera política para uma prática mais aberta e democrática.

Norris (2001), por sua vez, observando de que maneira a cultura digital impacta sobre a cultura política demonstrou, por meio de uma pesquisa empírica, como, nos países ocidentais ricos, há uma tendência para que a cultura digital - compreendida como o magma de conteúdos, ou como o senso comum - produzida por seus usuários, valoriza conceitos pós-materialistas, como liberdade e como generosidade, por exemplo. Na verdade, há certa tendência em Norris (2001) em compreender a cultura digital como um sucedâneo da contracultura dos anos 1960, o que talvez incida em 
certa simplificação da problemática dada. Mas, independentemente disso, parece acertada sua observação de que a cultura digital tem favorecido a articulação social em torno de causas democráticas e libertárias.

Nesse sentido, o advento da chamada Web 2.0, que significa a valorização da fluidez dos conteúdos em relação à produção dos mesmos, parece constituir um componente novo, capaz de intensificar essa tendência de uso cultural, e também político, do ciberespaço.

Evidentemente, sempre é possível acrescentar, a essas visões, a crítica de Jordan (2001), pela qual a cultura digital, ao contrário dessas proposições que apontam numa direção mais participativa, seria, na verdade, marcada pelos fundamentos individualistas próprios das culturas anglo-saxônicas e, dessa maneira, tenderiam a uma forma específica de política que não se pauta pelo tangível cooperativismo democrático antes tematizado. Essa avaliação é próxima à de Kumar (1997), que sugere que a cultura digital consiste, na prática, num processo de consolidação de padrões socioculturais já existentes, e não, como sugerem Lévy (1999), Scheer (1997) e Norris (2001), no estabelecimento de um novo padrão.

\section{Avaliação da Inclusão Digital na região Norte e no estado do Pará}

Não objetivamos uma avaliação exaustiva dos resultados obtidos pelo NavegaPará, mesmo porque ainda não há dados consolidados a respeito, mas sim o delineamento de algumas considerações gerais, que ajudem a percebem a forma de impacto do programa sobre a ID no estado do Pará. Para isso, partimos de uma observação da Pesquisa Nacional por Amostra de Domicílios (PNAD), desenvolvida pelo Instituto Brasileiro de Geografia e Estatística (IBGE) nos anos de 2005 - ou seja, antes do início da implementação do programa - e 2008, quando o programa tinha menos de dois anos do início de sua implantação, bem como da "Pesquisa sobre o uso das tecnologias da 
informação e da comunicação no Brasil", publicada em 2009 pelo Núcleo de Informação e Coordenação do Ponto BR, instituição vinculada Comitê Gestor da Internet no Brasil (CGI). São dados parciais, portanto, mas que permitem algumas aferições gerais e algumas considerações avaliativas.

A PNAD 2008 indica que, no Brasil, 55,89 milhões de pessoas de 10 anos ou mais de idade acessaram a internet por meio de um microcomputador, pelo menos uma vez, no período de referência de três meses. Estas pessoas representavam 34,8\% da população brasileira, mas apenas $27,5 \%$ da região Norte, o equivalente a 3,36 milhões de pessoas. No Pará, estado mais populoso da região, o índice foi de 23,9\% - 1,4 milhões de indivíduos, o que o torna o $4^{\circ}$ estado da federação com os piores índices de acessibilidade à rede, superior apenas ao Maranhão, Piauí e Alagoas.

Em relação à pesquisa PNAD 2005, percebe-se avanços significativos no campo da ID em todo o país. A acessibilidade do Pará, por exemplo, cresceu cerca de doze pontos percentuais, passando de $10,7 \%$ para os atuais $23,9 \%$, mas os índices ainda demonstram um hiato regional entre as regiões brasileiras. O Quadro 1, elaborado a partir de dados de CGI (2009), compara os principais índices de ID entre as regiões:

Quadro 1 - Comparação de índices de ID entre as regiões do Brasil

\begin{tabular}{|c|c|c|c|c|c|c|}
\hline Indicador & Brasil & Norte & Sudeste & Sul & Nordeste & Centro-Oeste \\
\hline Proporção de domicílios com computador & $32 \%$ & $19 \%$ & $43 \%$ & $40 \%$ & $14 \%$ & $34 \%$ \\
\hline Proporção de indivíduos que já utilizaram um computador & $53 \%$ & $47 \%$ & $60 \%$ & $57 \%$ & $42 \%$ & $57 \%$ \\
\hline Frequência de uso individual diário do computador & $58 \%$ & $55 \%$ & $60 \%$ & $58 \%$ & $51 \%$ & $55 \%$ \\
\hline $\begin{array}{l}\text { Local de acesso individual à internet - Centro público de } \\
\text { acesso gratuito }\end{array}$ & $5 \%$ & $7 \%$ & $6 \%$ & $4 \%$ & $3 \%$ & $6 \%$ \\
\hline Tempo gasto na internet por semana - De 1 a 5 horas & $49 \%$ & $54 \%$ & $56 \%$ & $48 \%$ & $55 \%$ & $50 \%$ \\
\hline
\end{tabular}

Fonte: Núcleo de Informação e Coordenação do Ponto BR/Comitê Gestor da Internet no Brasil. Disponível em: <http://www.cetic.br/usuarios/tic/2009total-brasil/index.htm>. Acesso em: 10 maio 2011. 
Dessa comparação, pode-se aferir, dentre outros, dois dados que sugerem uma evolução importante da ID na região Norte, provavelmente motivadas pelo NavegaPará, bem como por outros programas de ID que, embora menos impactantes, também foram implementados na região nesse período.

O primeiro dado diz respeito à forma de acesso à internet. Ainda que a Amazônia concentre o maior percentual de conexões à Internet por acesso discado (31\%) - o equivalente a onze pontos percentuais acima da média nacional - é, também, a região em que mais avançou a infraestrutura de acessibilidade, pois se observa uma queda de oito pontos percentuais, quanto a essa forma de acesso, em apenas um ano (2008-2009) (CGI, 2009, p. 125). O acesso discado é a modalidade mais dispendiosa de acesso e, por isso, atesta maior defasagem tecnológica de um determinado espaço. Esse dado, no entanto, parece indicar o impacto do NavegaPará sobre o Pará e a média regional, pois a rede de fibra óptica estabelecida pelo programa enfrenta, justamente e centralmente, o problema da defasagem tecnológica.

Outro índice positivo verificado na região Norte, nesse período, é o crescimento do número de domicílios com acesso à internet. Embora apenas 13\% dos domicílios da região façam parte dessa categoria - tal como, aliás, no Nordeste, contra 35\% do Sudeste, $32 \%$ do Sul e $28 \%$ do Centro-Oeste - a região Norte apresenta a maior taxa média de crescimento da acessibilidade domiciliar à rede: $25 \%$, um número expressivo quando comparado aos $15 \%$ do Nordeste; $22 \%$ do Sudeste; $21 \%$ do Sul e $20 \%$ do Centro-Oeste (CGI, 2009, p. 123).

Por outro lado, as dificuldades geográficas peculiares da região parecem apontar os principais desafios da ID, dentre eles a distância entre o mundo rural e o urbano. A região Norte apresenta a maior desproporção entre as áreas urbana e rural com relação ao uso do computador: 
Enquanto no total do país a diferença é de 24 pontos percentuais, verificados entre os $47 \%$ de usuários na área urbana e $23 \%$ na área rural, na região Norte essa diferença é de 30 pontos percentuais resultantes da distância entre os $12 \%$ anotados na área rural e os $42 \%$ da área urbana."

(CGI, 2009, p. 130)

De mesma forma, as variáveis socioeconômicas da região fazem com que a grande maioria dos usuários precise acessar a rede a partir de locais públicos, em geral pagos. Fica evidente que, para avançar na ID na região, é necessário investir em programas de acessibilidade em centros públicos gratuitos. Isso porque, a despeito do crescimento da acessibilidade domiciliar, os maiores percentuais de acesso à internet realizado em centros públicos de acesso pago, as chamadas lan-houses, estão no Norte e Nordeste. Na região Norte, 59\% dos usuários da rede o fazem através de uma lan-house, número ainda maior no Nordeste (63\%), e mais de $100 \%$ superior que a média das demais regiões (CGI, 2009, p. 136).

Essas duas variáveis dizem respeito à dimensão estrutural de um projeto de ID: ao nível da acessibilidade física, propriamente dita ou, ainda, a da experiência de acessibilidade tecnológica à cultura digital, tal como a caracterizamos anteriormente.

Porém, se avaliarmos a dimensão estrutural de um projeto de ID, ainda que a partir de dados temporalmente parciais em relação à experiência construída, tornase possível; avaliar, por outro lado, a dimensão político-subjetiva dessa mesma experiência, da forma como a discutimos anteriormente, é uma tarefa bem mais difícil, diante da ausência de vetores que a indiquem. 
No entanto, ainda que a simples acessibilidade seja um caminho, necessário, embora não mais que um caminho, em direção à resignificação cultural da política, é ponderável pensar que a acessibilidade possui uma dimensão subjetiva que valoriza e dignifica a pessoa a ponto de recolocá-la num papel político que é seu, deveras, embora a condição da exclusão digital lhe obliterasse.

O programa NavegaPará, tal como outros programas de ID, portanto, para além da materialidade física da acessibilidade, possui um impacto sociocultural que ressoa a experiência política da inclusão numa prática social que reorganiza e resignifica a própria política.

\section{REFERÊNCIAS}

AFONSO, Carlos A. Internet no Brasil: o acesso para todos é possível? Policy Paper, n. 26, set. 2000. Disponível em: <http://www.fes.org.br/media/file/analises_e_pro postas/policy_paper_26_2000.pdf>.Acesso em: 12 nov. 2010.

BOBBIO, Norberto. Estado, governo, sociedade: para uma teoria geral da política. 14. ed. Rio de Janeiro: Paz e Terra, 2007.

BOHMAN, James. Public deliberation: pluralism, complexity, and democracy. Massachusetts: MIT Press, 1996.

BUZATO, Marcelo El Khouri. Inclusão digital como invenção do quotidiano: um estudo de caso. In: Revista Brasileira de Educação, v. 13, n. 38 maio/ago, 2008. Disponível em: <http://www.scielo.br/pdf/rbedu/v13n38/10. pdf>. Acesso em: 20 de abr. 2010.

CAZELOTO, Edilson. A ideia de democracia nas políticas de disseminação da Internet: uma análise do "Livro Verde da Sociedade da Informação no Brasil". 2003. Dissertação (Mestrado em Comunicação e Semiótica) Programa de Estudos Pós-Graduados em Comunicação e Semiótica, Pontifícia Universidade Católica de São Paulo, São Paulo, 2003.

CGI - COMITÊ GESTOR DA INTERNET NO BRASIL. Relatório do Núcleo de Informação e Coordenação do Ponto BR. Brasília, 2009. Disponível em: <http://www.cetic.br/usuarios/tic/2009-total-brasil/index.htm>. Acesso em: 10 maio 2012.

GOVERNO DO ESTADO DO PARÁ. Mensagem à Assembléia Legislativa do Pará. Belém: Governo do Estado do Pará, 2010. 
GOVERNO DO ESTADO DO PARÁ. NavegaPará. Um sistema público de comunicação na Amazônia. Série Pará. Elementos de um novo modelo de desenvolvimento. Belém: Secretaria de Estado de Desenvolvimento, Ciência e Tecnologia, 2010.

JORDAN, Tim. Language and libertarianism: the politics of cyberculture and the culture of ciberpolitics. The Sociological Review, v. 49, n. 1, 2001.

KUMAR, Krishan. A Sociedade de Informação. In: KUMAR, Krishan. Da Sociedade Pós-Industrial à Pós-Moderna. Rio de Janeiro: Jorge Zahar, 1997. pp. 18-47.

LÉVY, Pierre. Cibercultura. São Paulo: Ed. 34, 1999.

NORRIS, Pippa. Cybercultura. In: NORRIS, Pippa. Digital divide: civic engagement, information poverty and the internet worldwide. Cambridge: Cambridge University Press, 2001.

PARTIDO DOS TRABALHADORES. Diretrizes de Programa 2011/2014 (Tese para discussão interna). Belém: Partido dos Trabalhadores, 2010.

PATEMAN, Carole. Participação e teoria democrática. Rio de Janeiro, Paz e Terra: 1992. pp. 92-98.

PONT, Clarissa. FSM é oportunidade para debater nova matriz de desenvolvimento. Carta Maior, 10 dez. 2008. Seção Movimentos Sociais. Disponível em: <http://www.cartamaior.com.br/templates/materiaMostrar. cfm?materia_id=15423>. Acesso em: 21 abr. 2010.

PROGRAMA NAVEGAPARÁ. Disponível em <http://www.navegapara.pa.gov.br/>. Acesso em 20 de mar. 2011.

SANTOS, Boaventura de Sousa. Democratizar a democracia: os caminhos da democracia participativa. Rio de Janeiro: Civilização Brasileira, 2002.

SCHEER, Leo. A democracia virtual. Lisboa: Século XXI, 1997. 